\author{
Dr F Hendricks \\ Faculty of Education, Nelson \\ Mandela University \\ Prof $L$ Wood \\ COMBER, Faculty of \\ Education, North-West \\ University
}

DOI: $h$ ttp://dx.doi.

org/10.18820/2519593X/pie.

v35i1.4

ISSN 0258-2236

e-ISSN 2519-593X

Perspectives in Education

2017 35(1): 40-53

(C) UVIUFS

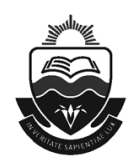

\section{An alternative approach to a complex issue: Youth- designed strategies for the prevention of teenage pregnancy in schools}

\begin{abstract}
Teenage pregnancy of school-going girls is a persistent concern, not only in South Africa, but globally. Despite various curricular responses aimed at educating young people about prevention, the numbers continue to rise. While recognising the intersectionality of teenage pregnancy, we believe that school-based prevention measures can play an important role in helping youth to make healthy decisions about their sexual behaviour. However, the effectiveness of the prevention messages depends on how they are designed and delivered. Using a participatory action research design, we engaged 24 peer educators in a process of data generation and analysis to help them to design, implement and evaluate prevention strategies that were found to be youth-friendly, contextualised and culturally relevant. This approach benefitted not only the participating youth in terms of the development of specific life skills, but also influenced how they, their peers and teachers began to think differently about the issue of teenage pregnancy. The research also influenced change in school policy. The findings thus indicate that the involvement of youth in finding ways to address issues that affect their lives may be an important way to improve the effectiveness of such programmes.
\end{abstract}

Keywords: participatory action research; participatory video; photo voice; sexuality education

\section{Introduction}

The number of teenage pregnancies in South Africa increased by over 30000 per annum between 2011 and 2013 - a situation that the Department of Education views as "alarming" (Masondo, 2015:1). In response, the South African Council for Educators and the government have called for change in the sexuality education offered in schools, the provision of condoms and more involvement from parents and other social services. This latter plea indicates that the government recognises pregnancy while still in school as a wider social issue, stemming from intersectional systems of oppression and inequality, rather than just being a symptom of ineffective education. While there are many incidences of rape, not to mention sexual abuse by teachers, the majority of pregnancies do occur 
as a result of teenagers having consensual sex (even if they are under the statutory age of consent).

We proceed from the viewpoint that current curricular approaches to sexuality education are geared more towards the moral stance of abstinence rather than recognising teenagers as legitimate sexual beings (Francis, 2010) who need to learn how to respond to their natural desires, without risking their future prospects. Pregnancy among school-going youth is mostly unplanned and there is ample evidence that it can have negative consequences for the teenage mother and more especially for the child (Ashcraft \& Lang, 2006; Kirby \& Lepore, 2007). Prevention of pregnancy among teenagers is also vital in light of the persisting HIV infection rate among 15-25 year olds (Pettifor et al., 2004). This also makes it imperative that condom use is promoted as the preferred method of contraception, rather than just hormonal contraceptives.

Teenage pregnancy among school-going youth is thus a complex problem, which needs to be addressed as part of a multi-pronged approach to improving the quality of life and life opportunities of youth and their communities (Panday et al., 2009). However, in the meantime, what can be done in schools to improve the sexuality education curriculum and, in particular, education about prevention of teenage pregnancy? This question was of concern to us as a teacher educator/researcher at a tertiary institution and a Life Orientation teacher in a school that has had up to 17 reported pregnancies per annum in the last few years (and several more unreported). Although the prevention of pregnancy is a topic in the subject Life Orientation, which all learners have to take, there are concerns about how it is (not) addressed by teachers for reasons ranging from not feeling comfortable or competent to talk about sex, to foregrounding their own moral and religious convictions (Nzioka \& Ramos, 2008). Sexuality education has not proven to be very successful in changing the behaviour of youth, since education divorced from their everyday life contexts does not engage young people, and may even have the opposite effect of alienating them (Francis, 2012: UNESCO, 2011).

Boonstra's (2015) review of international literature indicated that effective sexuality education helped to delay age of sexual debut and to debunk the many potentially dangerous myths that abound among youth. However, what is considered effective? Abstinence-only programmes aggravate a moral, judgemental approach to sexuality education, which is not effective among young people (Hacker et al., 2000). Merely imparting information also does not help (Kirby, 2011; Philliber, Kaye \& Herling, 2001). What does seem to have a better impact are programmes that involve youth in the creation of knowledge and that position them as experts in problems that affect their lives (Kegler et al., 2003). The findings of the first cycle of our research (Wood \& Hendricks, 2017) indicated that teenagers view their very lifestyle as high risk - just being teenagers and doing the things they enjoy make them vulnerable to having unprotected sex. So how do we help them to take precautions as they express their desires, needs and wants? One way would be to involve youth themselves in the design and implementation of prevention strategies, an idea that is being heralded in various countries (Boonstra, 2015). This led us to formulate our research question:

How might participatory methods help youth to create relevant and contextualised strategies for addressing teenage pregnancy?

In this article, we focus on the second cycle of an action research project with youth at a socially and economically disadvantaged school in South Africa. In the first cycle, 24 participating youth generated data about how they and their peers perceived teenage 
pregnancy and what they thought needed to be done about it (Wood \& Hendricks, 2017). Based on their findings, they developed prevention messages to address the topic in a youthfriendly, contextualised and relevant way. We first contextualise the research and explicate which theories influenced our choice of working with the youth in a participatory way, before explaining the methodology adopted. We then present the messages and related prevention strategies developed by the participants. We also present evidence of the influence these strategies had on the participants, other learners and teachers in this school and in other schools where they presented their prevention messages. The knowledge and methods we share in this article may be helpful to others who wish to engage with youth to address the issues of teenage pregnancy in their own specific contexts.

\section{Overview of larger action research project and development of prevention messages}

In this first cycle, we asked for volunteers from the existing body of peer educators in the school, who had undergone the basic peer educator training from the Department of Basic Education. Twenty-four participants (14 girls and 10 boys) agreed to take part after being briefed about the project. We adopted a participatory action research (PAR) design, because it combines research and action with the participant being central to the process (Jacquez, Vaughn \& Wagner, 2013).

We engaged with the youth participants to help them generate data about the dominant narratives of the young people in the school about teenage pregnancy, to educate themselves about the issue within their specific context before using this knowledge to help them to devise prevention strategies. The PAR process that was followed in this first cycle is reported on in detail elsewhere (Wood \& Hendricks, 2017), and suffice to say here that the youth participants gathered data from their peers, including some who were teen parents, in answer to the questions: "Why do you think teenage pregnancy is so common at our school? What impact does it have on a teenager's life, from your perspective? What do you think could be done to prevent it?" Drawing also on their own knowledge and experiences, their analysis of the data revealed three main themes: i) The very lifestyle of a teenager makes them high risk for teenage pregnancy; ii) The consequences of unplanned pregnancy can really mess up their life opportunities; iii) Sexuality education at school does not help them to practice safer sex. Based on the findings, the participants then developed messages that they thought should be disseminated to peers and, using a logic model framework (Kirby, 2001), determined which strategies would be most effective to deliver these messages. Figure 1 outlines this process.

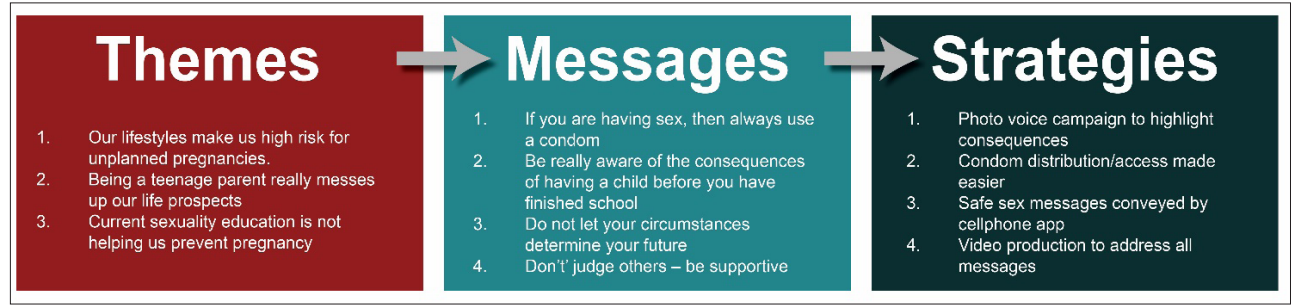

Figure 1: Development of prevention messages 


\subsection{Methods adopted in the second cycle}

We suggested photo voice and participatory video production in this cycle for the creation of prevention strategies because they embrace the prospect of unlocking a deeper understanding of teenage pregnancy and its impact as the youth in this school visualise it (De Lange et al., 2006). The artefacts created by participants allowed them to voice their opinions, perspectives and experiences around teenage pregnancy in a non-threatening manner (Bennett \& Roberts, 2004). These strategies allowed the participants to generate narratives by engaging them in dialogue, leading them to provide a story behind a story (Singh \& Matthews, 2008). The participants also decided on using a messaging application on their phones to share messages around condom use; to make condoms more easily available in school; and to disseminate their messages within their school and to final year learners in the neighbouring feeder primary schools. The participatory strategies used (photo voice; participatory video production) doubled as prevention strategies. This is common in the notion of research as social change (Schratz \& Walker, 1995) - while conducting data generation, the process is changing the way participants think, feel and act about the phenomenon in question.

For both photo voice and participatory video production (on separate occasions), we introduced the concept to them by explaining how they are used to promote change (Wang 1999). We facilitated a group discussion about the messages they wished to convey, based on their earlier research findings. For participatory video, they were divided into groups to make a storyboard to guide their shooting of the video. We then helped them to practise shooting photographs/ scenes. After giving them similar prompts -'Take photographs/make a video that represent the message(s) that you would like to give about teenage pregnancy" - they worked in groups to shoot the photos/videos. We also explained the ethical considerations of such processes. Each participant was involved in choosing photographs/scenes and in writing narratives to go with them. They viewed each other's photographs/videos and had a discussion around what it meant to them. We recorded these sessions, which served as rich data for analysis by the participants and ourselves later. The participants then decided on where, when and how to share these artefacts.

The usual ethical procedures were followed and the institutional ethics committee approved the study in line with the stringent criteria they set. Trustworthiness of the data was enhanced by multiple sources of data; a separate analysis by each researcher; participant analysis; and final consensus on findings validated by participants; as well as a detailed audit trail (Creswell, 2005).

\section{Theoretical framing}

Participatory action research is guided by a critical paradigm, which allows marginalised voices to become centre stage (Rodríguez \& Brown, 2009) and so performs an educative and transformative role (Babbie \& Mouton, 2010). A critical paradigm enabled us to work with them to raise their awareness of teenage pregnancy and enable them to devise strategies to deal with the issues it raises to improve the situation as it affects their lives (Mertens, 2009). Although guided by this critical and transformative paradigm, we also drew on the more interpretive social learning theory (Bandura, 1977) which explains behaviour as an outcome of interaction between environmental factors, intrapersonal factors and how people make sense of these. Too many programmes to prevent pregnancy focus on individual factors, for example assertive training. This is not effective because social factors also play an important role in influencing sexual behaviour. Social learning theory posits that behaviour is learnt; therefore, change can be effected by providing new learning experiences. The three factors: 
environment, thinking and behaviour are constantly influencing each other. Behaviour is not simply the result of the environment and the person, just as the environment is not just simply the result of the person and behaviour (Glanz et al., 2002). The aim in this study was for peer educators to provide environmental inputs that would speak more effectively to the individual youth and create a climate where teenage pregnancy was viewed as "uncool" and thus hopefully influence them towards making healthier behavioural choices. At the same time, participation in the project would increase their personal skills, honing their capacity for leadership and critical thinking.

\section{Discussion of findings}

In presenting the data, codes are used to ensure participant anonymity and to indicate the data source. The abbreviation (Pn) refers to participant and (FGn) refers to the focus group discussions with other learners. These participants were quoted verbatim. The discussion is structured according to the messages the participants identified based on their analysis of data in cycle one (see Wood \& Hendricks, 2017). For each message, we indicate how it was conveyed within the various strategies and critically discuss how this approach might be more likely to make an impact on their target audience in comparison with the usual strategies used by teachers and other adults. We also present evidence of the influence that participation in the project had on the peer educators, and the ways their strategies influenced their peers, teachers and ultimately school policy.

\subsection{Message 1: If you are having sex, then always use a condom}

This message was repeated through the various strategies, but was most directly addressed in one of the videos created by the participants. The poster created from the photographs by one group of participants (Figure 2) sends a strong message to use condoms, by using an acronym of some sort: Come On Now, Do Oppose pregnancy until Marriage.

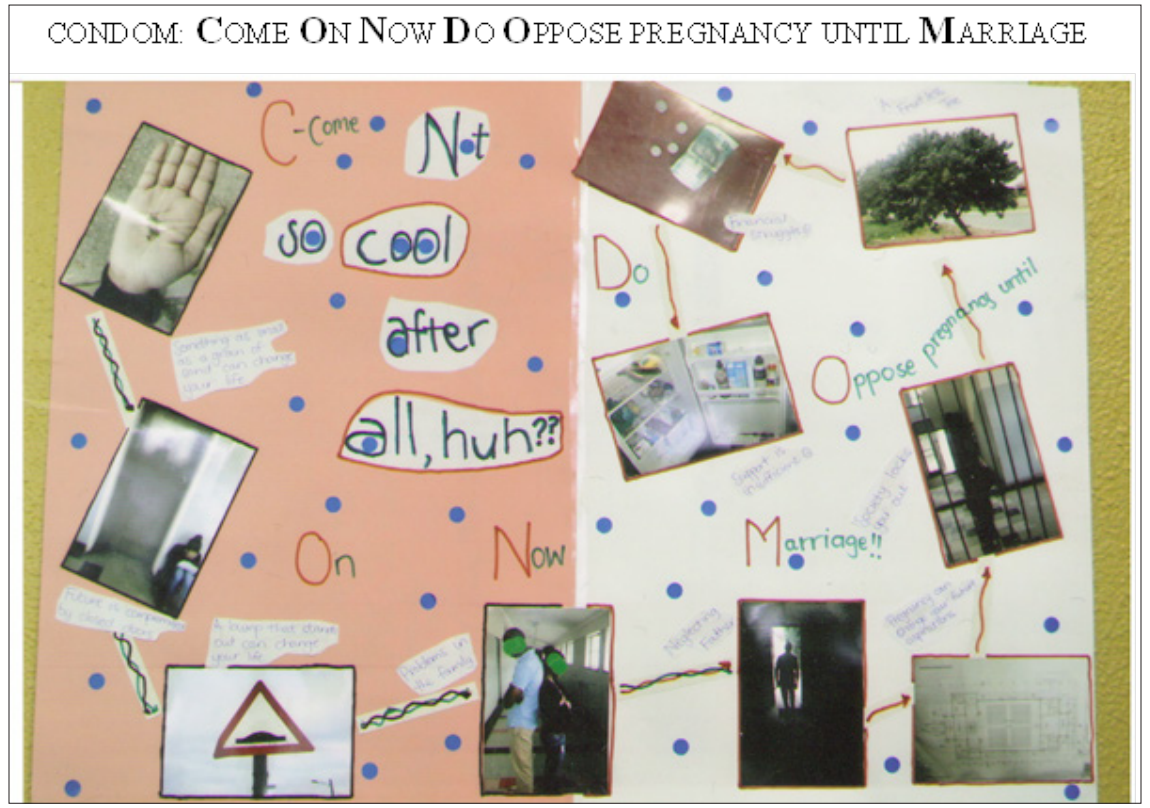

Figure 2: Promoting condom use 
Notably, the message is not that they should not have sex until marriage, but that they should take precautions to make sure they do not fall pregnant. This is in contrast to the usual messages so often conveyed by teachers and parents. The images in this poster point out the consequences of teenage pregnancy and position it as "uncool", but the message also recognises that young people are capable of making responsible choices about their own behaviour. It recognises that they are legitimate sexual beings (Francis, 2012) and that if they decide to engage in sex, then they should be adult enough to protect themselves against the negative and far-reaching consequences portrayed in the poster.

The video entitled "It's your choice!" (https://youtu.be/8CJHdOSX7rA) clearly portrays the responsibility of youth with regard to their sexual behaviour. This video was humorous as the main characters were based on a local soap opera popular with the youth. The language is colloquial and typical of how the young people talk, mixing English and Afrikaans and highlighting the common myths that were identified in the data in cycle one (e.g. you don't get pregnant when you have sex for the first time!). The actions of the characters, although exaggerated somewhat, are typical of how the young people talk and act. This video portrays the young man as a womaniser, but instead of this boosting his popularity and image, he ends up a "loser" and at the end entreats the audience to make the sensible choice and use a condom. By highlighting the ability of the youth to make responsible, "adult" choices, the message may be more likely to be given serious consideration than if abstinence is preached as the only choice. Even when a more comprehensive approach is adopted towards sexuality education, the message of adopting safe sex practices is more likely to be given as a command - e.g. you must protect yourself - rather than conveyed in a humorous, contextually relevant way by people the youth identify with, as it is in this case.

In addition to campaigning for the use of condoms through visual material, the participants also requested that condoms be placed in a specific room in the school, so that learners could access them without any embarrassment. This was the first time that school management had agreed to have condoms available on school premises, therefore, their actions had some impact on school policy. They also told their peers that they were available to answer any questions about contraception. Another strategy they adopted was to send pictures via WhatsApp to peers in their contact lists of a condom demonstration by a local nurse with short messages such as "when you stand up, cover up!" and "make the right choice, condomise". Actions such as this helped to raise awareness within the school and open up discussions among the learners.

Contrary to the fear that making condoms available may entice the youth to have sex, recognising their ability to make responsible choices may have the opposite effect:

It improved my decision; it strengthens my abstinence of having sex before marriage (FG7).

There was also evidence that it changed the way that the participants thought about their behaviour in general:

Doing the photos and videos made me become more responsible not only in a sexual way; to be more responsible as a person. It made me look at a girl in a different way. I have more empathy for the girls (P5).

Using music, humour and familiar language, using images and scenarios that resonate with the youth, the message to practise safe sex was thus delivered in a way that was 
attractive to the youth audiences. It was also encompassed within the message that young people are responsible enough to make choices that will enhance their future prospects, a positive representation of youth that they may aspire to - and which incidentally is one of the key features of the Life Orientation curriculum, contained in the principle of setting high expectations and encouraging learners to attain them.

\subsection{Message 2: Be really aware of the consequences of having a child before you have finished school}

This message was addressed primarily in the photo voice campaign, but also touched on in the videos. Participants took photographs, symbolic of the message they wanted to put across and wrote narratives to accompany them. They used the same photographs to create composite posters (see Figures 3a/b.) and individual photographs.

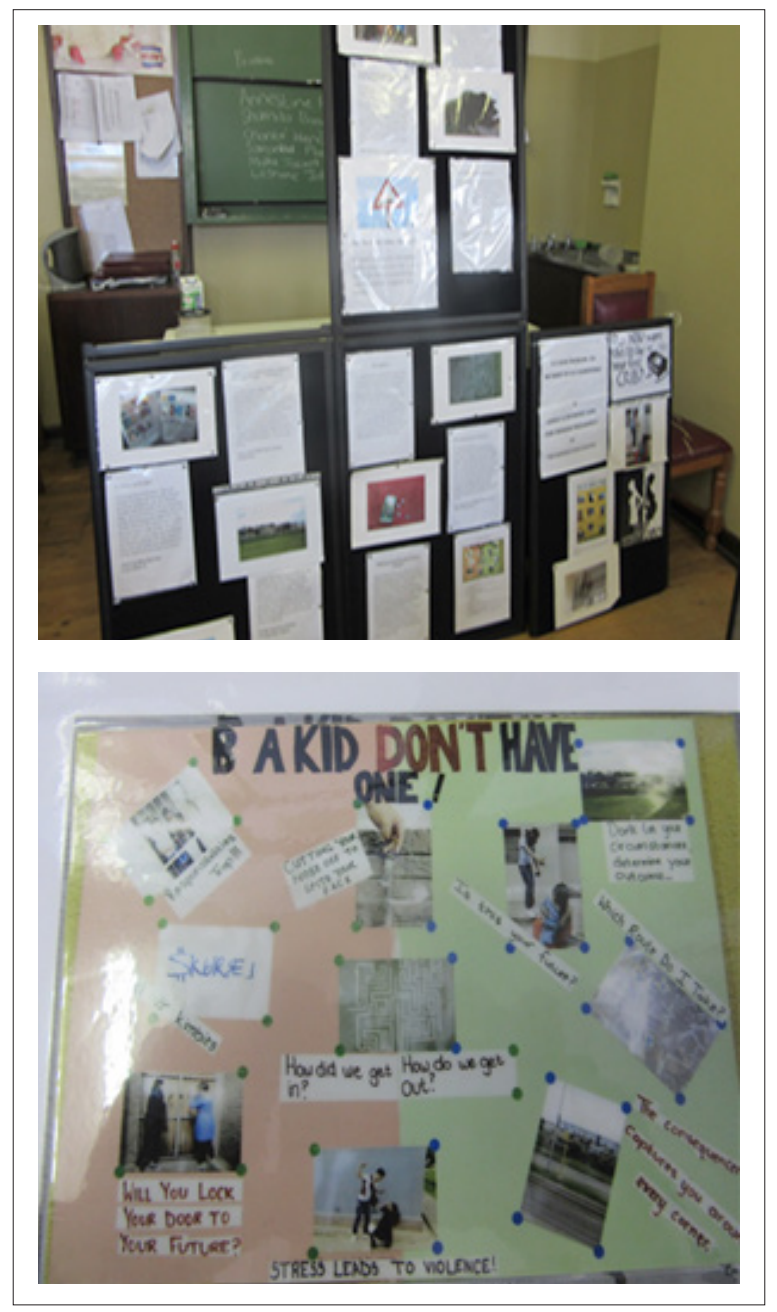

Examples of photo voice display and posters

Figure 3a: Examples of photo voice display and posters 


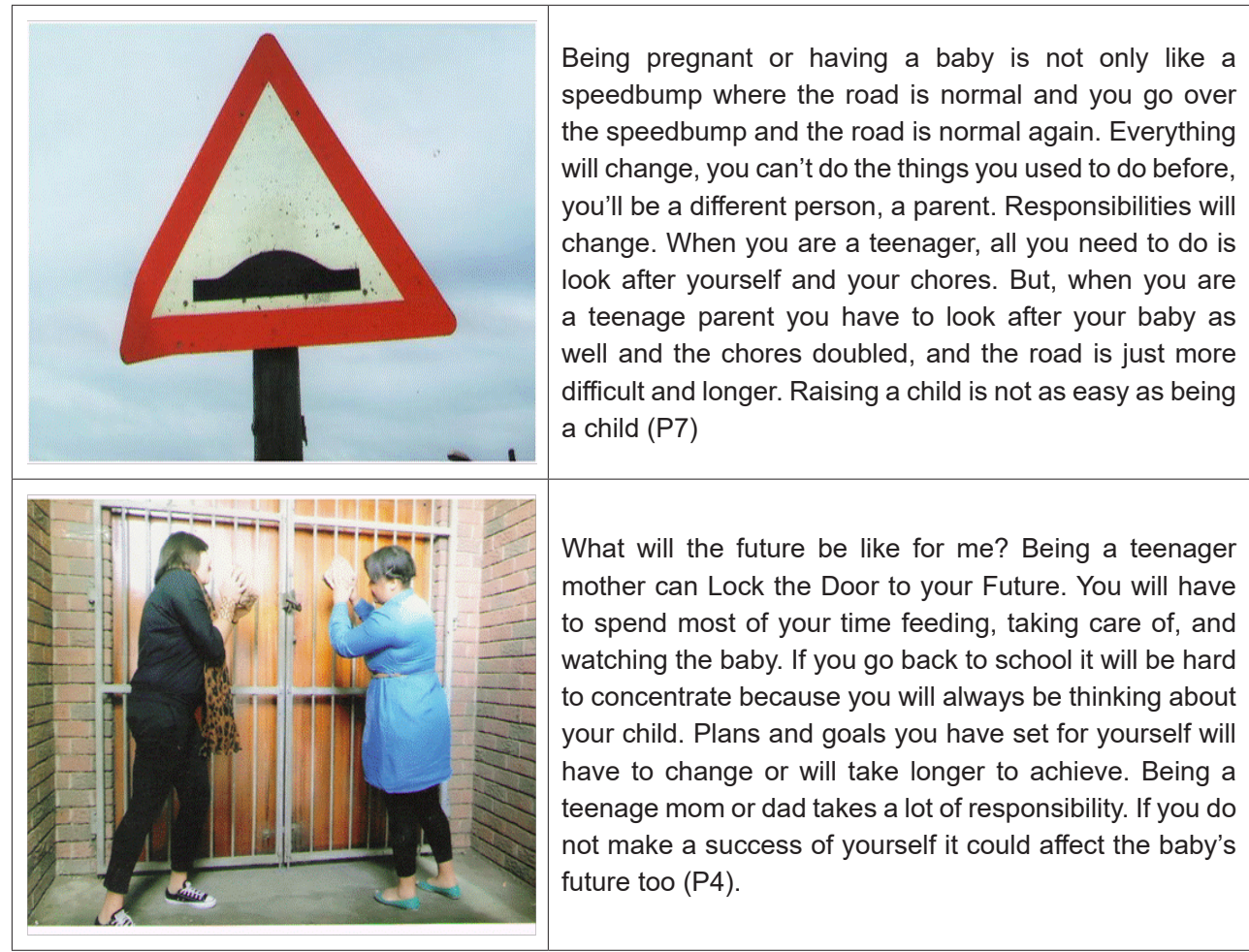

Figure $3 \mathbf{b}$ :Photos about the consequences of teenage pregnancy

The messages conveyed in the photo voice images again place the responsibility for decisionmaking with the youth, while also conveying the seriousness of the far-reaching consequences of having a baby before you have finished schooling. The use of language like "Skurrel vir Kimbies" (see Figure 3a) (hustle for nappies) speaks to the context of the young people who come from an impoverished community where "hustling" to survive is commonplace. In addition, notable in the one poster (Fig.3a) are that the participants pose questions, rather than give answers e.g. Will you lock the door to your future? This approach encourages the viewer to think about their response, and recognises their agency, rather than admonishing them NOT to do something as most adult messages are framed. The use of images depicting male on female violence, gangsters and prison-like doors also arouse the emotions of the audience, since they are images that evoke scenes and experiences they encounter on a daily basis. Many of the youth at this school come from homes where domestic violence is commonplace; gangsters cruise the streets and try to recruit young people; and having a relative in prison is not an unusual occurrence. Since deep learning is a social and emotional experience, and not just a cognitive one (Fletcher, 2015), the messages may be more likely to be internalised due to the emotions evoked and the familiar social settings in which they are portrayed. Social learning theory also emphasises the importance of messages being conveyed by people and in contexts to which the audience can relate (Bandura, 1997).

Both the videos portrayed the possible negative consequences of not making healthy choices, but also highlighted the positive outcomes of taking precautions to protect against pregnancy. Again, the settings and topics portrayed were familiar to the youth, showing the 
usual scenes of girls feeling unloved by parents and turning to boys for solace; boys taking advantage of this to persuade girls to have sex - but also of girls who are willing to have unprotected sex and youth who choose not to have sex. The learners who viewed the videos agreed that in general they spoke to their lives: It happens, your friend is sleeping with your friend, which is supposed to be your best friend (FG6). When asked what main message they will take away, two replied:

It is your choice. (FG3)

Learn from your friend's mistake, instead of bumping your head or get hurt. No turning back. (FG7).

There is no judgement contained in the videos, and different attitudes and behaviours are portrayed, but the underlying theme is that it is up to the youth to make the right choice.

The viewing of the videos also evoked critique by some learners who claimed the one scene did not reflect the reality of the power of the girl to say no: "[it is] not realistic - the girl can never say no in real life! When the boyfriend scenario happened it was too easy. No challenges. It was too easy for her to get out' (FG2). Several of the audience said they would like to remake a more realistic video and asked to be included in the peer educator group the following year.

Yes, but we want heavy one's. We are going to take it deeper. It must be more realistic (FG8).

By making the videos and creating the photo voice artefacts, the peer educators were aiming to raise awareness, evoke discussion and get their peers to think more deeply about their options with regard to sex, and reactions such as these indicate that they have had some degree of success.

It made us more aware of all the consequences: emotional, financial consequences and responsibility wise. If you get pregnant, you will have a lot of responsibilities; you will have to drop your education and all of that. So it made us more aware to make other people aware of this serious thing and it needs to stop (FG5).

Rather than alienating their audiences by being prescriptive, they managed to open up a space for dialogue and dissenting voices to be heard.

\subsection{Message 3: Do not let your circumstances determine your future}

As in many communities all over South Africa, the youth in this one faces challenges to access employment or further study opportunities after they leave school (Banerjee et al., 2008). This can lead to a sense of hopelessness, which makes them more vulnerable to unhealthy coping mechanisms (Zimmerman, 2013). The data analysis in the first cycle informed the participants that there was a need to address context since current sexuality education did not consider it and therefore it is a strong theme in one of the videos (https://www.youtube. $\mathrm{com} /$ watch?v=iSK9iQqVIS8\&feature=youtu.be). The participants portray a bullying father who walks out on his family and a mother who is not interested in the life of her teenage daughter. This drives the girl into the arms of her boyfriend who sees it as a chance to convince her to have sex. The outcome is positive in the end but the content evoked much discussion among the youth audience who could identify with the family portrayed in the video. Some of them were instilled to join the "fight" against teenage pregnancy: 
The images are effective in depicting the realities our learners encounter on a daily basis (FG8).

We must save each other's lives. We must lower the teenage pregnancy percentage (FG6).

The participating peer educators stated that involvement in the project had made them more aware of the need to take action to change their social circumstances and to spread the message to others that they can also improve their circumstances:

We don't want our world to be like that. We must take a right decision for our children. That is why we must step in now before it is going out of hand (P7).

I feel it is our duty to go there and share our knowledge and tell others about the consequences of teenage pregnancy and that they do not need to fall into that trap (P6).

The participants had named the project "Gelvanise", a play on the name of their school and the idea of galvanising into action. It appears that participation in the project has indeed helped to mobilise them into doing something.

\subsection{Message 4: Don't' judge others - be supportive}

The final message deemed necessary to address the themes identified was to counter the judgemental attitudes towards those who became teen fathers or mothers, and towards those who went to the clinic to obtain contraception. The video "Don't let your background determine your future" suggests that young people can find help and support from the peer educators, rather than from those who might wish to manipulate their feelings for their own purposes. It aimed to raise awareness of the judgement young people face and to show that such attitudes did not help to improve the situation. Some of the comments made after watching the video and viewing the photo narratives included:

It is good to know you have friends when you go through difficulty and that people cares for you (FG5).

The presentations show how difficult it is to continue life after teenage pregnancy as well as the shame involved (FG1).

The manner in which learners are ostracised when pregnant is clearly illustrated (FG9).

An element of understanding seemed to be developing which indicated that they were experiencing more empathy towards each other:

Girls must be taught that they have so much to look forward to and accomplish, and that falling pregnant can be [a] major obstacle on a path to a better future, although it isn't always a 'dream-killer', if it happens. Instilling a sense of self-worth in girls [as] often as possible is vital if we are to see our girls flourish (FG13).

This more accepting and helpful attitude towards each other is important to instil, since statistics tell us that only about one third of teenage mothers (Panday et al., 2009) return to school largely due to the stigma and lack of support they experience (Welsh, 2016). Even the teachers who viewed the photographs and videos could see the need for support, rather than judgement, as one commented: 
Teenagers are overburdened with stresses and problems that make 'normal functioning' on a daily basis an impossibility. These teenage girls need a space where they are able to speak and be heard by an adult that will take in the information, offer advice or assistance, and be non-judgemental. It is important to make an effort to really listen to what these girls have to say (T1).

Participants in this project also benefitted in terms of developing leadership skills, communication skills and an understanding of how important it is to be inclusive and to listen to all points of view, as the following extracts indicate:

It makes it real. Like to hear it from another person's viewpoint. You might have your own. Hear it from other people. You might see it from another point. I can add it to my knowledge. (P4)

Yes, because what people says give you a broader aspect, so you can take a better decision. You will think twice. Differently (P7).

It learnt me how to treat my girlfriend. To respect yourself as well, It made me more mature. (P3).

I have learnt communication skills, negotiating skills, problem-solving and to be assertive (P5).

Hopefully, the peer educator participants will share their knowledge with the other learners, as is their stated intention:

We are going to get other learners on board. Younger learners so that they can continue with the process (P9).

We are the seniors of the school. The learners listen to us (P6).

We think it may be more than coincidence that out of the 24 participants, 20 did go onto study further at college or university in 2016.

\section{Concluding discussion}

The prevention strategies employed by the youth in this project seem to have had some success in spreading messages that speak to the concerns identified by them in cycle one of the project. The evidence presented in this paper (and it was only possible to present a fraction of the evidence due to limited space) seems to suggest that the strategies devised by the participants helped to convey the seriousness of the consequences of falling pregnant while at school. It also pointed out the agency that learners can have in this respect - they do not need to fall into the same patterns as others just because they come from "difficult" backgrounds. It also helped them to realise the need to support if they are to help each other to make healthy decisions, rather than judging their peers for "making mistakes". The style of language, sense of humour and incorporation of scenes and images that resonated with the daily lives of the youth helped the messages to have impact and provoked discussion and critique - the core aim of visual methods as research for social change (Schratz \& Walker, 1995).

Of course, the problem with peer education programmes is that the peers who are trained move on each year, therefore the sustainability of any change is not assured (Morar et al., 2016). However, using visual methods to create artefacts means that the incoming peer educators have examples to follow when they create their own strategies. Teachers can use 
the existing artefacts that they know resonate with the youth of this school to enable discussion within sexuality education, hopefully making it more relevant to the learners, while helping the teacher to feel more comfortable with a topic that s/he might not be trained to/want to address.

The research question we addressed in this article was:

How might participatory methods help youth to create relevant and contextualised strategies for addressing teenage pregnancy?

We are able to conclude that, although the reduction of teenage pregnancy needs a multisector approach, the process of involving youth in educating their peers can do much to raise awareness and shift thinking about the phenomenon. The youth in this project focused on social risk factors that render young people more vulnerable to making unhealthy choices, and did so in a way that showed they understood the adversities facing them, rather than moralising about it. Although we value Kirby's (Kirby, Obasi \& Laris, 2006) recommendations about the characteristics of effective sexuality education programmes, we suggest that this project not only encompassed many of them, but also allowed for the missing voice of the young people concerned to be heard. Kirby stresses the importance of involving expert adults in the design of programmes, but we argue that this has to be complemented by participatory methods that allow the target audience (youth) to introduce more contextually relevant and age appropriate material. Involving youth in finding ways to reduce the incidence just might prove to be more effective than the usual adult-devised programmes and strategies. The value of such a project is enhanced by the fact that it can be run within school hours, using the normal breaks or time allocated to Life Orientation or similar subjects. The idea of participatory design of teaching material can also be done in any Life Orientation class, rather than as a specific project for selected peer educators.

To conclude: some good news - the incidence of teenage pregnancy at this school in 2014 and 2015 dropped from an average of 15 over the past few years to just 2 cases. We do not in any way claim that this was just because of the project, but maybe it did have some impact?

\section{Acknowledgement}

This study was funded by a grant from the NRF. Any opinion or finding presented herein are those of the authors and the NRF cannot accept any responsibility thereto.

\section{References}

Ashcraft, A. \& Lang, K. 2006. The consequences of teenage childbearing. Working Paper 12485 ,

Babbie, E. \& Mouton, J. 2010. The practice of social research. Cape Town: Oxford University Press.

Bandura, A. 1997. Self-efficacy: The exercise of control. New York: W.H. Freeman \& Company. https://doi.org/10.1111/j.1468-0351.2008.00340.x

Banerjee, A., Galiani, S., Levinsohn, J., McLaren, Z. \& Woolard, I. 2008. Why has unemployment risen in the new South Africa? Economics of Transition, 16(4), 715-740.

Bennett, F. \& Roberts, M. 2004. From input to influence: Participatory approaches to research and inquiry into poverty. York, UK: Joseph Rowntree Foundation. 
Boonstra, D. 2015. Advancing sexuality education in developing countries: Evidence and implications. In J Ponzetti Jr (Ed). Evidence-based approaches to sexuality education: A global perspective. London: Routledge.

Creswell, J.W. 2005. Educational research: Planning, conducting and evaluating quantitative and qualitative research, $2^{\text {nd }}$ ed. Upper Saddle River, NJ: Pearson Education.

De Lange, N., Mitchell, C., Moletsane, R., Stuart, J. \& Buthelezi, T. 2006. Seeing with the body: Educators' representations of HIV and AIDS. Journal of Education, 38(1), 44-66.

Fletcher, M. 2015. Professional learning. In O. Zuber-Skerritt, M. Fletcher \& J. Kearney (Eds.). Professional learning in higher education and communities: Towards a new vision for action research. Basingstoke, UK: Palgrave-Macmillan. https://doi.org/10.1057/9781137455185_2

Francis, D. 2012. Teacher positioning on the teaching of sexual diversity in South African schools. Culture, Health \& Sexuality, 14(6), 597-611. https://doi.org/10.1080/13691058.201 2.674558

Francis, D. 2010. Sexuality education in South Africa: Three essential questions. International Journal of Educational Development, 30(3), 314-319. https://doi.org/10.1016/j. ijedudev.2009.12.003

Glanz, K., Rimer, B.K. \& Lewis, F.M. 2002. Health behavior and education. Theory, research and practice. San Francisco: Wiley \& Sons.

Hacker, K.A., Amare, Y, Strunk, N \& Horst, L. 2000. Listening to youth: Teen perspectives on pregnancy. Journal of Adolescent Health, 26 (4), 279-288. https://doi.org/10.1016/ S1054-139X(99)00110-X

Jacquez, F., Vaughn, L.M. \& Wagner, E. 2013. Youth as partners, participants or passive recipients: A review of children and adolescents in community-based participatory research (CBPR). American Journal of Community Psychology, 51(1-2), 176-189. https://doi. org/10.1007/s10464-012-9533-7

Kegler, M., Rodine, S., Marshall, L., Oman, R. \& McLeroy, K. 2003. An asset-based youth development model for preventing teen pregnancy: Illustrations from the HEART of OKC Project. Health Education, 103(3), 131-144. https://doi.org/10.1108/09654280310472351

Kirby, D. 2001. Emerging answers: Research findings on programs to reduce teen pregnancy. Washington, DC: National Campaign to Prevent Teen Pregnancy.

Kirby, D. 2011. The impact of sex education on the sexual behaviour of young people. Expert Paper No. 2011/12. United Nations Department of Economic and Social Affairs. New York: United Nations.

Kirby, D. \&. Lepore G. 2007. Sexual risk and protective factors: Factors affecting teen sexual behavior, pregnancy, childbearing and sexually transmitted disease: which are important? which can you change? Washington, DC: National Campaign to Prevent Teen Pregnancy.

Kirby, D., Obasi, A. \& Laris, B.A. 2006. The effectiveness of sex education and HIV education interventions in schools in developing countries. Technical Report Series-World Health Organization, 938, 103.

Masondo, S. 2015. Teen pregnancies hit 99000 a year. Available at http://www.news24.com/ SouthAfrica/News/Teen-pregnancies-hit-99-000-a-year-20150905 [Accessed 12 July 2016].

Mertens, D.M. 2009. Transformative research and evaluation. New York: Guilford. 
Morar, N. S., Naidoo, S., Goolam, A. \& Ramjee, G. 2016. Research participants' skills development as HIV prevention peer educators in their communities. Journal of Health Psychology, 1-7. Doi:1359105316655470.

Nzioka, C. \& Ramos, L. 2008. Training teachers in an HIV and AIDS context: Experiences from Ethiopia, Kenya, Uganda and Zambia. Paris: International Institute for Educational Planning.

Pettifor, A., Rees, H., Steenson, A., Hongwa-Madikezela, L., MacPhail, C., Vermaak, C. \& Kleinschmidt, I. 2004. HIV and sexual behaviour among young South Africans: A national survey of 15-24-year-olds. Johannesburg: University of Witwatersrand.

Panday, S., Makiwane, M., Ranchod, C. \& Letsoala, T. 2009. Teenage pregnancy in South Africa: With a specific focus on school-going learners. Human Sciences Research Council. Available at http://www.hsrc.ac.za/en/research-outputs/view/4542 [Accessed18 July 2016].

Philliber, S., Kaye, J. \& Herrling, S. 2001. The national evaluation of the Children's Aid Society Carrera-Model Program to prevent teen pregnancy. Accord, NY: Philliber Research Associates.

Schratz, M. \& Walker, R. 1995. Research as social change: New possibilities for qualitative research. London: Routledge

Singh, P. \& Matthews, J. 2008. Visual methodology and ethnographic un/knowing. Australian Association for Research in Education Conference, Brisbane, 30 Nov.

Statistics South Africa. 2015. General household survey, 2014. Pretoria: Statistics South Africa.

Rodríguez, L.F. \& Brown, T.M. 2009. From voice to agency: Guiding principles for participatory action research with youth. New Directions for Youth Development, 2009(123), 19-34. https:// doi.org/10.1002/yd.312

UNESCO. 2011. WHO guidelines on preventing early pregnancy and poor reproductive outcomes among adolescents in developing countries. Geneva: UNESCO.

Wang, C.C. 1999. Photovoice: A participatory action research strategy applied to women's health. Journal of Women's Health, 8(2), 185-192. https://doi.org/10.1089/jwh.1999.8.185

Welsh, E. C. 2016. The negative effects of stigma on adolescent pregnancy and motherhood. Journal of Psychology, 26, 17-31.

Wood, L. \& Hendricks, F. 2017. A participatory action research approach to developing youthfriendly strategies for the prevention of teenage pregnancy. Educational Action Research, 25(1), 103-118. https://doi.org/10.1080/09650792.2016.1169198

Zimmerman, M. A. 2013. Resiliency theory. A strengths-based approach to research and practice for adolescent health. Health Education \& Behavior, 40(4), 381-383. https://doi. org/10.1177/1090198113493782 